\title{
EL DESIERTO PRODIGIOSO Y EL PRODIGIO DEL DESIERTO (1650) DEL NEOGRANADINO PEDRO DE SOLÍS Y VALENZUELA: LOS ESPACIOS DE LA LITERATURA
}

POR

\author{
Sibylle María Fischer \\ Duke University
}
O tempo cresce e sobra, e se a pessoa pega a escrever, não há papel que baste. Machado de Assis

El desierto prodigioso y prodigio del desierto, voluminosa obra miscelánea escrita en el Reino de Nueva Granada alrededor de 1650 y descubierta recientemente, parece, para el lector moderno, un texto paradójico. Como texto en prosa, se justifica por la poesía; como obra de ficción aspira a la veracidad. Los recitales poéticos hablan del silencio, y los diálogos alaban el monólogo. El texto se ramifica y desdobla por cientos y cientos de páginas, y mientras el manuscrito termina en medio de la frase, sabemos que un personaje llamado Don Pedro ya está organizando más material para lo que sería un segundo volumen. La edición moderna nos dice, además, que el autor real, el clérigo Pedro de Solís y Valenzuela, murió sin haber terminado y publicado su libro. ${ }^{1}$

El resultado de este proyecto inacabado es un texto que contiene vastos pasajes de poesía (tanto original como citada de otros autores), dos obras teatrales (una tercera se ha

\footnotetext{
' El único manuscrito completo de El desierto prodigioso se descubrió en 1963 en la biblioteca de la Fundación Lázaro Galdiano en Madrid. En 1970 se encontró otro manuscrito en Medellín, que incluye una versión más elaborada de los primeros tres capítulos, algunos poemas y dos comedias. (Para una historia más completa de las vicisitudes de los manuscritos, véase Páramo Pomareda XIIXXIII.) El Instituto Caro y Cuervo de Colombia se encargó de la preparación y publicación de los manuscritos. El primer volumen del texto integral salió en 1977. En 1984 se publicó una versión abreviada, limpiada de casi todo lo que no pertenece al marco narrativo, con el subtítulo "Primera novela hispanoamericana". En el mismo año salió el segundo tomo del texto integral, y en 1985 el tercer tomo, que contiene los tres capítulos del manuscrito de Medellín. Parece que un cuarto tomo va a aparecer pronto. Hasta el momento, El desierto prodigioso no ha obtenido la atención que merece, tanto por su complejidad como por su estatus singular dentro de la literatura hispanoamericana de la época colonial. Aparte de las introducciones y los estudios de los editores Páramo Pomareda, Briceño Jáuregui y Paéz Patiño, dedicados al texto mismo y a los varios contextos socio-culturales, históricos y geográficos, hay solamente dos estudios, uno de Rodríguez-Arenas sobre El desierto prodigioso como producto textual de la Contrarreforma, y otro, de alcance más limitado, de Chibán y Altuna, dedicado a la intertextualidad entre el Siglo de Oro español y El desierto prodigioso.
} 
perdido), cartas, relaciones autobiográficas, diálogos, textos historiográficos, leyendas y hagiografias, los que están ligados sueltamente por un marco narrativo. Es este marco al que algunos críticos han llegado a considerar la primera novela hispanoamericana. ${ }^{2}$

$\mathrm{La}$ acción del marco es simple. Cuatro jóvenes de clase social alta y desmesuradas inclinaciones religiosas emprenden una excursión de caza en el Reino de Nueva Granada. Habiendo descubierto por casualidad la cueva del ermitaño Arsenio, éste les cuenta la historia de su vida, los anima en su lectura de textos edificantes y fomenta su producción y recitación de poesía. De este punto parten las conversiones prodigiosas que dan el título al libro.

La pregunta que se plantea, tal vez, con más urgencia al lector moderno gira en torno al volumen de la obra. ¿Cómo explicar esta enorme proliferación de textos heterogéneos, dado que el marco cuasi-novelístico ofrecía un modelo de integración mucho más rigurosa? Es cierto que en el S. XVII obras misceláneas, fueran de carácter religioso o no, florecieron tanto en España como en sus colonias, mientras las formas novelescas de los siglos anteriores se estaban disolviendo. En este sentido El desierto prodigioso no sale de lo típico. A partir del ideario barroco de engaño y desengaño, hace gala de su conciencia aguda de los problemas de realidad y ficción, de escribir y vivir, de tradición literaria y experiencia religiosa, sin aspirar a una integración completa de los materiales narrativos. Es por esto que una terminología concebida para evaluar los altibajos en el desarrollo de la novela no puede captar las características de esta obra excéntrica.

Uno de los logros inesperados de El desierto prodigioso es cierta correspondencia entre estructura textual y desarrollo de la acción: traza la imposición de la vida religiosa sobre la vida de los jóvenes y, simultáneamente, sobre el repertorio literario tradicional. ${ }^{3}$ El desierto prodigioso crea un espacio ambiguo que podemos entender como resultado de un intento de salvar la literatura. Espiritualmente, la quiere salvar del pecado y de la perdición por la vanidad mundana; institucionalmente, se puede especular, la quiere salvar de la persecución y condenación por la Iglesia de la Contrarreforma. Dejando del lado el aspecto institucional, en lo sucesivo me referiré especialmente a las implicaciones formales que tiene la salvación espiritual; pero tal vez no esté demás mencionar el hecho de que un libro de estructura semejante a la de El desierto prodigioso - El viaje entretenido del autor español Rojas Villandrando- ya estaba en el Index librorum prohibitorum et expurgatorum cuando el clérigo, y miembro del Oficio de la Inquisición, Pedro de Solís

\footnotetext{
${ }^{2}$ Mientras Orjuela mantiene que $E l$ desierto prodigioso es la primera novela hispanoamericana (5183), Briceño Jáuregui insiste que "no puede clasificarse El desierto en un género particular porque es un hibridismo de narrativa, historia, costumbrismo, ascética y novela" (15). Puesto que en este estudio me propongo indagar la estructura del texto integral y no me limito a las partes que se podrían considerar novelísticas, el problema de si El desierto prodigioso es o no es novela no me concierne. Tampoco voy a entrar en la discusión de la historia y de los principios de la novela en Hispanoamérica (para una discusión de algunos criterios teóricos e históricos más exhaustiva véase Goic 369-375; para una breve discusión de las particularidades del contexto neogranadino, véase Briceño Jáuregui 363 et seq.).

${ }^{3}$ Para un análisis de las huellas que la Contrarreforma y su apropiación del arte como instrumento de propaganda moralizante dejaron en el texto, véase Rodríguez-Arenas.
} 
estaba compilando y redactando su texto (Joset XXIV). ${ }^{4}$ Visto desde esta perspectiva, no es tan sorprendente la convergencia entre el reino de la estética y de la moral, que, en $E l$ desierto prodigioso, no alcanzan sino un balance transitorio. Encontramos esta contradicción en todos los niveles de la obra: las tradiciones literarias existentes se salvan, pero se eliminan sus particularidades; se recrea el espacio literario a través del estilo culto, pero son suprimidos los aspectos liberadores de la ficción y de las fantasías populares; al desescribirse, la novela queda salvada.

\section{LABERINTOS, SIGNOS Y JEROGLÍFICOS}

Los personajes de El desierto prodigioso se mueven por un mundo de signos. Se comunican a través de la lectura y escritura de textos, perciben a sus compañeros como signos de una realidad espiritual, y sus penas y alegrías se les presentan alegóricamente. Arsenio "más parecía retrato de la muerte que cuerpo de mortal creatura" (I: 152). Leonor/Delia, la mujer amada por Arsenio en su juventud, parecía un "geroglífico de perfecciones" (I: 265). El Cristo crucificado es un "geroglífico tan cierto y verdadero de la mortal agonía" (I: 133), y Arsenio inventa "[v]arios enigmas" "para tener más presente" su dolor sobre la muerte de su esposa (I: 271). Antonio, no tan buen poeta como dibujante, acompaña a los otros ilustrando sus versos (por ejemplo I: 126 y II: 774). El mundo de los signos incluso determina el desarrollo de la acción. El incidente que provoca todos los acontecimientos del marco es el encuentro de los cuatro jóvenes con el ermitaño Arsenio. Sin embargo, este evento no se inicia con el encuentro de los personajes sino con el descubrimiento de unos "mal formados caracteres, por estar ya cubiertos del verde belo de la peña" (I: 12), lo que le causa al protagonista "el ardiente desseo de penetrar el misterioso secreto de aquel tosco padrón” (I: 12 et seq.). A continuación descubre una lápida, notas, carpetas, versos y pinturas con inscripciones. Sólo después de haber interpretado debidamente todos los signos enigmáticos, los cuatro jóvenes llegan a conocer al ermitaño. Pero entonces ya estamos en la $4^{\mathrm{a}}$ Mansión. $^{5}$

$\mathrm{Ni}$ siquiera el lector está exceptuado de esta ley de acceso interpretativo al "desierto prodigioso": el libro empieza con un "laberinto" que, una vez descifrado, resulta en un cuarteto en alabanza del autor Solís y Valenzuela. Y hay otros acertijos. Algunos personajes,

\footnotetext{
${ }^{4}$ El viaje entretenido (1602-03) fue uno de los libros más populares del s. XVII en España. Como El desierto prodigioso tiene un marco narrativo (el encuentro de varias personas en un viaje) que sirve para reunir versos y escritos misceláneos. Además, coinciden en un detalle curioso en $E l$ desierto prodigioso, un ciervo conduce a Andrés a la cueva del ermitaño; en el libro de Rojas un puerco montés cumple una misión casi idéntica (Briceño 367 et seq.). Pero, obviamente, estas semejanzas en sí no prueban que Pedro de Solís hubiera conocido la obra española. Otra coincidencia entre El desierto prodigioso y El viaje entretenido se relaciona con la pertenencia genérica de las dos obras: como en el caso de El desierto prodigioso, hay poco acuerto entre los críticos, y las clasificaciones vacilan entre "costumbrismo", "miscelánea", "novela picaresca" y "miscelánea dialogada" (Joset XXVII-XXXIV).

${ }^{5}$ La obra se divide en 22 capítulos, llamados "Mansiones", lo que quiere decir "ratos de esparcimiento religioso y literario, descansos o permanencias, que hoy llamaríamos sesiones" (Páramo Pomareda LVI).
} 
por ejemplo, tienen nombres que revelan su significado cuando se invierten las letras: Casimira se puede leer como "casi-mia", "Arsenio" como "será-yo", Ascanio como "Acasoyo" (Orjuela 68). Arsenio admite que su nombre verdadero no es Arsenio sino que lo heredó de otro ermitaño, y al terminar la obra ya hay un tercer Arsenio, que adopta el nombre en memoria del segundo.

Esta fascinación por los signos encuentra su expresión más completa en la concepción de la escritura. Por regla general, las conversiones no se dan sino después de la lectura de un texto. El primero en caer bajo el poder de la palabra escrita es Andrés, al descubrir los escritos del ermitaño Arsenio. Éste a su vez confiesa que se convirtió al leer los escritos de Casimira, la mujer a la que él había raptado para casarse con ella (I: 295 et seq.). El "venerable padre [de los jóvenes], aviendo leydo las cartas y testamento de su hijo, [...] enpezó a despojarse del mundo" y se hace ermitaño (II: 715). Don Jacinto, clérigo algo despreocupado, llega a leer las Meditaciones que Andrés había encontrado en la cueva, y decide entrar en un monasterio de cartujos (II: 695-702). El caso más interesante es tal vez el del campesino español Pedro Porter, quien, en búsqueda de un texto escrito, desciende hasta lo más profundo del infierno (I: 396-415 y 464-480). Un notario no había documentado debidamente el reembolso de una deuda, y cuando éste muere, Pedro Porter no tiene prueba de su pago. Visita al notario en el infierno, donde éste le revela el lugar en el que había escondido el documento. Así sale de sus calamidades, sólo para meterse en más dificultades porque la gente no le cree su minucioso relato sobre las penas del infierno, y lo toma por estafador. Otra vez necesita documentos y testimonios para probar la veracidad de su relato, esta vez frente a la Inquisición, la cual decide al final, basándose en todos los escritos, que dice la verdad. ${ }^{6}$

De todo esto podemos inferir varias características de la relación entre el mundo de los signos y el de los hechos: primero, parece que un hecho no está completo y terminado sin que lo afirme un signo o la palabra escrita, y que hechos no confirmados se exponen a la duda; segundo, que los signos visuales tienen más fuerza para provocar una acción que la palabra hablada o los hechos; y aquí finalmente, que los signos proliferan. Sin entrar, en una discusión de "palabras y cosas" (discusión que por cierto exigiría una base de datos

\footnotetext{
${ }^{6}$ Según Páramo Pomareda, el cuento de Pedro Porter está copiado, "con respeto de su lengua y estilo, de documentos conservados entonces en la Cartuja del Paular" (LVII). Esto podría indicar que el interés en la escritura y en los procedimientos burocráticos no es una idiosincrasia de Solís sino que se trata de un fenómeno más común de la época. Ya que sería difícil determinar el origen preciso de la leyenda de Pedro Porter, no se puede sino especular sobre las posibles modificaciones que haya experimentado ésta comparada con sus fuentes. Llama la atención, sin embargo, que en ninguna de las tradiciones más conocidas sobre visiones del infierno, los escritos y los trámites burocráticos juegan un papel importante. (Y mientras es bastante común el encontrar a un abogado en el infierno, parece que en la mayoría de los casos se encuentra alli por sus pecados - la mentira, el robo, etc.- y no por su negligencia burocrática.) Véase, por ejemplo, Le Goff, quien en su estudio sobre el nacimiento del purgatorio, da un excelente bosquejo de la gran variedad de narraciones - tanto de la antigúedad como de origen medieval- sobre el mundo de los muertos. En los textos que discute - todos escritos mucho antes de El desierto prodigioso- ya encontramos la gran mayoría de los detalles del cuento de Pedro Porter. Para un panorama general de narraciones sobre el infierno, desde los llamados libros apócrifos del s. II y IV hasta las visiones ocurridas hacia finales del s. XIII, véase la antología Visions of Heaven and Hell Before Dante.
} 
mucho más amplia ${ }^{7}$ ) se puede sugerir que para el autor de $E l$ desierto prodigioso la relación entre los hechos y los signos, y especialmente signos literarios, se ha problematizado. De hecho, el proyecto de Solís sería reprochable desde el punto de vista de la Iglesia si la relación no fuera inestable: solamente si la relación entre signos y hechos, entre género y material temático no es natural, el proyecto de re-interpretación y traslado de la literatura secular al espacio de la literatura religiosa es justificable. El problema de los signos es que, en vez de revelar la realidad última y definitiva, se convierten en otra apariencia que a su vez exige más interpretaciones, traducciones, ilustraciones, glosas, etc. Ya sea porque ninguno de estos sistemas de significantes es capaz de captar el hecho por completo, o porque ninguno de los signos es completamente inteligible y transparente, o simplemente porque la relación entre signos y hechos es arbitraria, las representaciones de la experiencia religiosa nos desengañan y engañan a la vez, revelando el significado escondido bajo las apariencias, y seduciéndonos a producir más apariencias.

Esta lectura está confirmada por la epistemología implícita del texto. A pesar del intelectualismo que se expresa en la afición a los enigmas, acertijos y juegos meta-ficticios, el mundo está velado a la razón: "más que lo racional, pareze que informa al hombre lo caduco" (I: 91 et seq.). ${ }^{8}$ Es la experiencia que desengaña al hombre. Pero, paradójicamente, la experiencia misma forma parte del mundo engañoso y, por lo tanto, debe ser interpretada. La solución de esta contradicción que ofrece El desierto prodigioso es tan ingeniosa como imposible. Solamente la experiencia mediatizada por la escritura y por los signos puede captar/producir el desengaño; pero el resultado mismo de este proceso de mediación -el signo en su realidad física y seductora - produce otro engaño. Tampoco es posible resolver esta contradicción por un acto voluntarista, pues el poner fin a la multiplicación de las palabras significa distorsionar el mundo aún más:

[A] unque es verdad [...] que las [i.e. las poesías] pudiera ceñir a pocos versos, mi devoción no me ha permitido que observe las leyes rigurosas de la poesía, assí en lo concisso y conprehensivo como en el metro (II: 264).

El desierto prodigioso no puede terminar porque las prescriptivas de los diferentes géneros poéticos tratan de las palabras más en cuanto objetos estéticos que en cuanto representaciones de una realidad otra. Encontramos con cierta regularidad advertencias de uno de los personajes (o del narrador) de que $E l$ desierto prodigioso no es un "certamen poético, ni menos academia" (I: 275) sino un ejercicio espiritual, en el que no hace falta "gallardía de palabras sino llaneza de conceptos" (II: 280). Dejando de lado por un momento las consideraciones epistemológicas, vale la pena señalar que el texto hace referencia a un

${ }^{7}$ Uno de los intentos más ambiciosos de indagar estas cuestiones es, obviamente, The Order of Things de Foucault. Éste postula un profundo cambio epistemológico a principios del siglo XVII, cuando empieza lo que él llama "la edad clásica", caracterizada por la idea de que el reino de los signos no existe independientemente de la cognición humana (59).

${ }^{8}$ Otros ejemplos para este tópico tan repetido son: “ $\mathrm{O}$ encantada ceguedad / de la razón sin govierno!" (I: 145); "contra la razón que lo difficulta [...] arguye la experiencia que lo convenze" (I: 92); “jO, despierte ya la insensibilidad rebelde de la razón a golpes tan penetrantes!" (I: 107). Para un análisis de la relevancia política de la desconfianza del intelecto, véase Maravall (131-173 y 400 et seq.). 
fenómeno que, según sugiere Carilla (39 et seq.), se puede considerar una de las fuentes de inspiración de las obras misceláneas del Barroco español e hispanoamericano. Academias y torneos poéticos eran un elemento importante en las numerosas fiestas oficiales que sirvieron para la ostentación del poder de los señores coloniales, y como tales, las academias -y las obras misceláneas inspiradas en aquéllas - llevan la huella de la condición colonial de Hispanoamérica. Se podría incluso sostener que, en el caso de El desierto prodigioso, es posible considerar la fiesta colonial como el punto de enlace entre la forma interna, según la analizo aquí, y la escritura como práctica social. Cabe recordar, sin embargo, que El desierto prodigioso refleja un doble conflicto. Por un lado, el rechazo de todo lo que sea cotidiano o, como veremos más adelante, popular, refleja la imposición de una cultura oficial sobre los individuos y la literatura de la época; respecto a esto imita y asimila la estructura de las academias y fiestas coloniales. Por otro lado, el intento de trasladar los géneros literarios cultos al ámbito de la religión católica es reflejo de un conflicto entre la autoridad secular y la autoridad eclesiástica; y esto es lo que conduce al rechazo de la concepción de El desierto prodigioso como fiesta secular o como "academia".

Volviendo al texto mismo, podemos afirmar que el discurso literario en El desierto prodigioso se establece como búsqueda de la expresión definitiva e inequívoca de la verdad religiosa. Lejos de la actitud "realista" de quien confia en lo que ve y en lo que dice, ${ }^{9}$ para el autor barroco el mundo de los signos se convierte en símbolo del engaño y clave para el desengaño. En vez de revelar la complejidad del mundo y las equivocaciones de los conceptos humanos, actitud que corresponde más a la novela en el sentido que le da, por ejemplo, Bakhtin, aquí tenemos un discurso que trata de eliminar ambigüedades, traduciendo todas las lenguas al estilo culto y tratando de agotar el sentido de las manifestaciones de la religión católica. Esto, sin embargo, no deja de ser una actitud contradictoria. El narrador como predicador rechaza las ambigüedades y la multiplicidad seductora de las apariencias y de los signos. Como escritor se halla fascinado por su riqueza inagotable: "Don Pedro, llevado de su furor poético, no pudo menos que prorrumpir escriviéndole estos versos [...]" (II: 814).

\section{LA ENCICLOPEDIA}

Sería un texto monstruoso - similar tal vez a lo que Borges alguna vez ha llamado "novela caótica"- el que no obedezca a otra ley que la de la proliferación de signos y del furor poético. El texto mismo lo advierte:

\footnotetext{
${ }^{9}$ Hay, sin embargo, cierta preocupación por la verosimilitud (lo que no se debe confundir con la obsesión omnipresente con la veracidad del cuento). El siguiente comentario se debe entender como elogio de Don Pedro como poeta: "[...] pareze que en esta descripsión y pintura a querido dibuxar este desierto, pues más bien le convienen las deffinidas propiedades que no al prado del negro Egipto." (I: 519). En otro lugar se menciona una "danza de gitanas, fingidas, porque allá no las ay, pero suplían muy bien la color la de los yndios" (II: 523). En otro contexto el narrador discute la imposibilidad de captar la santidad de cierto monasterio y compara su dilema con el de un pintor griego, quien, después de varios intentos malogrados de dar representación a un gigante, no pintó sino un dedo (II: 796 et seq.).
} 
[N]i he guardado las reglas del arte en la poesía, y de la canción me he passado a hazer sylva, y aun no sé a lo que mi pluma me precipitara, si ella misma, temerosa de su riesgo, no me huviera advertido del empeño tan grande en que la iba metiendo (II: 796).

Pero El desierto prodigioso no sufre de un diseño caótico sino de un control excéntrico. La falta de unificación textual y la tendencia hacia la digresión no significan que no haya límites:

No con saynetes de dichos agudos, no con la salsa de las murmuraciones ni con el picante de los chistes, dieron refección a la naturaleza estos quatro jóvenes, sino que imitando al Profeta Rey comían con el pan ceniza de la sepultura (I: 126).

La peculiar combinación de lo alimenticio con los géneros literarios de la cultura popular en este párrafo recuerda lo que dice Bakhtin sobre la relación entre la cultura popular, su interés carnavalesco en las funciones digestivas y sexuales del cuerpo y los orígenes de la novela. No cabe duda de que Solís hubiera querido cortar esta conexión: el registro alto de la literatura religiosa debe absorber y eliminar la vulgaridad revoltosa de la expresión popular. El desierto prodigioso es un intento de establecer la literatura como literatura culta religiosa. Un buen ejemplo para este procedimiento es la leyenda ya mencionada del descenso de Pedro Porter al infierno. Con su énfasis en los procedimientos jurídicos y las pruebas documentadas, Solís remoldea, desde la perspectiva oficialista de la Inquisición, un tipo de cuento que se ha difundido a través de los "exempla" en sermones dentro y fuera de la iglesia y que tiene incontables versiones populares (Le Goff 297 et seq.).

En resumidas cuentas, aparte de la limitación literario-social, hay un solo criterio: que el cuento "no saliesse de la esfera de sus asumptos" (I: 204). Dentro de estos confines el texto se puede mover libremente. El tema - la vida religiosa y la alabanza de Diospuede encontrar infinitas variaciones a no ser que la variación salga del ámbito de la literatura culta. Otra vez estamos frente a una estructura que ya vimos en los signos: el lazo problemático entre el signo y el objeto señalado tiene su paralelo en la relación arbitraria entre el material temático y los géneros literarios. Y como en el caso de los signos, esta arbitrariedad produce variaciones sin límites.

El contar de la vida de San Bruno es una de las muchas ocasiones en que se despliega el "furor de variaciones". Empieza con Arsenio, quien cuenta la historia en prosa. Sigue inmediatamente un epigrama en latín sobre el mismo tema. Fernando traslada el epigrama latino a un soneto en español, Pedro escribe variaciones en octavas, Antonio ofrece otro soneto y Arsenio concluye la primera serie con un tercer soneto. En la Mansión siguiente, se añaden glosas, más octavas y más sonetos (I: 423-429 y 449-463).

En este juego de variaciones, la mayoría de los textos intercalados no tienen justificación a nivel de la acción. Es la veracidad de lo contado, en vez de los requisitos del contar, lo que justifica la integración de más y más cuentos. Arsenio, por ejemplo, cuenta la leyenda de un hombre que durante su vida había sido un pecador atroz y, ya muerto, se levanta una última vez para amonestar a sus amigos. Don Fernando tiene dudas en cuanto a la veracidad, lo que provoca un discurso de casi veinte páginas de Arsenio (II: 55-74) en el que explica en detalle quien confirmó la historia, quien la negó, discute los argumentos e incluye una lista tan larga de testigos que el narrador dice que la pone al 
margen del texto para no interrumpir el fluir de la historia (II: 69). ${ }^{10}$ El narrador se ve forzado a narrativizar los márgenes del manuscrito para suavizar la contradicción fundamental entre el fluir del cuento y la verdad de lo contado.

Ahora, las variaciones no ocurren sin adaptación y modificación del género original. El cuento autobiográfico de Arsenio es tal vez el mejor ejemplo. ${ }^{11}$ Es la novela bizantina que le presta la forma a la juventud de Arsenio. El núcleo de la acción es una historia de amor que pone en marcha las intrigas y culmina en el rapto de la mujer amada, la cual debe vestirse de hombre y cambiar su nombre de Casimira a Ascanio. La peripecia es la conversión de Casimira y Arsenio: termina la novela bizantina y empieza la novela pastoril en la que viven en cuevas, fabrican versos y van vagando por la naturaleza, sin ocupación otra que la del canto. Lo importante de este procedimiento es que algunas de las características más notables de los géneros seculares se han perdido en esta traducción, las reminiscencias paganas de la novela bizantina y pastoril se han reprimido, y lo fantástico - ¿lo utópico? - ha desaparecido en la supuesta realidad biográfica de la futura monja y del futuro ermitaño. La etapa pastoril no es sino etapa de transición y nunca se estabiliza. Sin duda, ésta no es la única posibilidad de tratar los géneros intercalados. El Don Quijote es una muestra de esto. Ahí las novelas insertadas crean universos ficticios diferentes, dominados por leyes incompatibles, ${ }^{12}$ mientras El desierto prodigioso devora los géneros intercalados al trasladarlos a la esfera purificada de la literatura religiosa. El universo de la novela pastoril no se distingue del universo de los protagonistas o del narrador, y se borran las incompatibilidades entre los diferentes mundos. Saltando de un mundo a otro, el Don Quijote cita, imita y se ríe de las leyes de la ficción; El desierto prodigioso, arraigado firmemente en el mundo del catolicismo barroco, purifica y desecha, para elogiar lo que queda: las leyes del estilo culto.

De este modo, El desierto prodigioso crea una enciclopedia de los géneros en su aplicación religiosa. Para crear un espacio para la literatura dentro del mundo de la religión (y viceversa), la trama debe pasar por el mayor número de géneros posible. El desierto prodigioso muestra que el estilo elevado aparentemente monológico y dogmático no es algo dado, algo gratuito que se puede imponer en un acto voluntarista. Al contrario, el texto tiene que transformar, asimilar y re-escribir todos los discursos literarios para llegar a esta uniformidad. Así el texto produce una resonancia de los lenguajes y géneros transformados y excluidos, pero al mismo tiempo traza, no hay que olvidarlo, los actos de represión que lo constituyen.

\footnotetext{
${ }^{10}$ Encontramos este afán de probar la verdad de lo contado a docenas: aparte de la historia de la vida de San Bruno, en la historia del monasterio, en la historia sobre el origen de la vida religiosa, sin hablar de la técnica más frecuente que es usar a uno de los personajes como "transcriptor" y testigo de un acontecimiento.

${ }^{11}$ Otros ejemplos incluyen un poema "ajustad[o] al estilo corriente y común de las audiencias, que entre procuradores, letrados y relatores" que adapta la jerga jurídica a la doctrina católica (I: 99 et seq.) y una "égloga piscatoria" para la descripción del traslado por mar de unas reliquias, la que profundamente transforma el género bucólico (I: 343-363).

${ }^{12}$ Sigo aquí el argumento de Martínez-Bonati, quien llama a los universos incompatibles del Quijote "regiones de la imaginación".
} 


\section{Prosa y POESÍA}

Aproximadamente un tercio de El desierto prodigioso consiste de versos. En las partes más elaboradas del texto la poesía está propiamente integrada en la trama en el sentido de que provoca, resume o repite los sucesos. ${ }^{13}$ En la mayor parte del libro, sin embargo, la relación es bastante vaga y el lazo con el texto en prosa es puramente temático: los placeres de la fe, las penas del infierno, la buena muerte. La mayoría de los versos se atribuyen a uno de los personajes, y algunos se identifican como poemas de otros autores, principalmente del Siglo de Oro.

En el caso de las atribuciones ficticias se da, según nos dicen los editores, un fenómeno curioso. En los márgenes del manuscrito hay tachaduras en las que se pueden descifrar los nombres de los autores verdaderos (ya vimos anteriormente que los márgenes constituyen un espacio ambiguo entre ficción y realidad en El desierto prodigioso). El autor adapta, por ejemplo, un poema de Fray Luis de León y lo pone en boca de Casimira, cambiando las formas masculinas a femeninas y modificando el contenido según la situación particular de ella (I: 291). En otra ocasión atribuye un poema a Don Pedro, pero en el margen del manuscrito da a saber que es de un tal D. Gabriel de Moncada (I: 99). Puesto que a veces se sugiere que Don Pedro es el mismo autor de la obra, esta atribución ficticia sorprende. No cabe duda de que para el autor de un libro tan acosado por los requisitos de la veracidad el atribuirse a sí mismo la autoría de poemas ajenos sería un pecado imperdonable. Otra vez vemos aquí que el texto vacila entre la veracidad de lo contado (los nombres al margen del manuscrito) y la narrativización completa (atribución de los poemas a uno de los personajes).

Dada la cantidad de versos en El desierto prodigioso, cabe preguntar cuál es la función que cumplen en la obra. Obviamente, el despliegue de la poesía es parte de la enciclopedia de los géneros y esto explica en parte aquel exceso. Además, los pronunciamientos poéticos del texto mismo parecen sugerir que la poesía simplemente embellece la prosa. ${ }^{14}$ Pero hay otra conceptualización de la poesía que la clasifica de "órgano del cielo" (I: 32). Al lado del espaciamiento horizontal de la prosa, por decirlo así, la poesía como "órgano del cielo" parece ser la única forma superior, más cerca del significado último que los otros signos. Mientras la prosa describe el mundo de los fenómenos, la poesía - por lo menos en la variante que encontramos en El desierto prodigioso- se abstrae del mundo y se agota en la visión meditativa de la vida y de Dios. La prosa debe provocar las acciones, mover a los

\footnotetext{
${ }^{13}$ Los versos que Andrés encuentra al iniciarse la acción del marco se pueden leer como una especie de profecía de los eventos de la obra. Véase también los veinte sonetos que preceden la vida de Arsenio, ... y que cuentan la historia bíblica del hijo pródigo (I: 241-251), las conversiones provocadas por la poesía y el caso de Leoncio, el cual termina con la ejecución de Leoncio en verso (I: 173-185). ${ }^{14}$ En uno de los discursos meta-literarios más exhaustivos Pedro dice: "La historia [...] escrita en prosa es comparada a vna matrona noble y honesta, cuyo vestido ha de ser muy grave y circunspecto, sin consentir superfluo ornato. Mas la historia escrita en verso es semejante a la esposa de un rey, adornada no solamente de oro y púrpura, sino de vistosos broches de flores y otras joyas de diversas piedras preciosas que hazen más apazible su magestad. Y, assí, llevado de mi devoción a la matrona honesta que nos a propuesto Arsenio en la historia de San Bruno [...] he procurado hazerla reyna [...]" (II: 265).
} 
personajes por el espacio del libro, crear un mundo en el que la gente actúe y siga hablando. La poesía, en cambio, niega precisamente este mundo. Lo que parece loable en los versos de Casimira, por ejemplo, es "el desengaño que Casimira sabía sacar de las flores, plantas y árboles" (II: 355), y de algunos versos de Antonio se dice " $\mathrm{O} O$ cómo nos a enseñado Antonio [...] a levantar el corazón a Dios Nuestro Señor y a las cossas celestiales y eternas, de todo lo visible y terreno!" (I: 320). La tensión es obvia: por un lado, la poesía es vehículo por excelencia del ascetismo, por otro, es el género embellecido y frívolo que distrae de la contemplación seria de los misterios de la religión $-\mathrm{y}$ de ahí los frecuentes rechazos de una atención exagerada hacia lo formal de la poesía. ${ }^{15}$ De este modo, la poesía participa en el despliegue de paradojas en El desierto prodigioso: está más cerca de la realidad que la prosa en cuanto no participa en la acción ficticia, y al mismo tiempo está un paso más alejada en cuanto reelabora experiencias ya ficticias. Trata de eliminar las contingencias mundanas y al mismo tiempo crea nuevas distracciones por su exceso de adorno. Así, la poesía se inserta entre la narración ficticia y el mundo real del autor y crea un reino que no pertenece a ninguno de los mundos por completo.

\section{DiÁlOGO, MONÓLOGO Y SILENCIO}

En vez de seguir una prescriptiva específica como la de la épica, del soneto, etc. Pedro de Solís introduce su propia teoría sobre el valor de la lengua y la jerarquía de sus usos. Hablar y escribir, preguntar y contestar se convierten en uno de los hilos temáticos, y como tal tiene su propio desarrollo: habiendo pasado por cientos de páginas de diálogos, recitales y discusiones sobre la vanidad mundana, el lector sabe que las Mansiones no son sino antecámaras del silencio. "In silentio et spe erit fortitudo vestra" (II: 171) podría ser el lema de El desierto prodigioso, y como tal provoca otro dictado de diez páginas de versos.

Los diálogos, en el nivel más bajo, sobresalen por su anti-realismo. Es casi imposible distinguir las voces de los cinco personajes principales, y su manera de hablar apenas difiere del discurso escrito del narrador. ${ }^{16}$ Todos usan latinismos, e incluso al campesino Pedro Porter se le escapa un "gracias os hago" (I: 475). ${ }^{17}$ Todos saben recitar docenas y docenas de poemas sin notas y sin atragantarse, y tanto sus repertorios como su interés por los versos parecen inagotables.

Hecho interesante también es la manera en que se introduce el estilo directo: empieza una oración sin indicaciones gráficas de que hable un personaje y, ya avanzada, aparece el nombre del interlocutor entre paréntesis. Esto ocurre incluso cuando cambia el hablante:

Por cierto (repitieron todos) floridamente lo pensó el florido ingenio que lo conpuso, y con justa razón le da magestuosa collocación [...] Lorenzo Gracián, y avéys, Antonio, excedido a todos con sola su relación tanto gustosa quanto digna de multiplicarse a la

\footnotetext{
${ }^{15}$ Compárese también II: 811.

${ }^{16}$ Compárese el lapso del propio narrador quien confunde el hablar y el escribir de sus personajes: cuando Arsenio está a punto de empezar a contar la vida de San Bruno, se inserta un "antes de escrevir" en el texto (II: 3; mi énfasis).

17 Véase I: 475 , nota 96.
} 
estampa. ¿Ay desgracia más cruel (dixo Dn. Fernando) que la fineza con que esta flor más lizonjea, venga a ser cuchillo que la despedaze? ¿Es posible que cossa tan bella [...] aya villana mano que la corte y desperdicie su purpúreo ornamento? Posible es (respondió Don Andrés) y viene a ser alto exemplar para nuestra enseñanza [...] (I: 95).

Mientras en el mundo real la voz ocupa cierto espacio y se distingue por la melodía y la tonalidad, este párrafo elimina la voz quitándole el espacio de resonancia, asimilando las voces de los personajes, callando las cualidades físicas.

Hablando como quien escribe, los personajes raras veces intercambian ideas o pensamientos directamente. El libro empieza con un encuentro retrasado por cuatro capítulos y termina con un intercambio de cartas. Casi parece como si los personajes buscaran la comunicación más mediatizada posible: comunican sus emociones con versos y cartas, leen juntos y escriben comentarios sobre lo que leen, para leer estos comentarios en voz alta a sus amigos. Los diálogos directos, sin referencia a otro texto, nunca comunican ideas esenciales y cuando alguien dice algo memorable sin referencia a un texto ya existente, hay que crear un nuevo texto.

El resultado de esta técnica es que a lo largo de la obra se elabora una especie de canon de textos y opiniones comunes. Cada uno puede contribuir a la discusión con lo que considere esencial o lo que haya experimentado, y así El desierto prodigioso llega a representar la summa de la experiencia religiosa. Los textos escritos por los personajes se declaran explícitamente destinados a integrar este canon, y los personajes-autores pasan a otro nivel de ficcionalidad, oscilando ahora entre meta-ficción y realidad.

"[P]retendo [...] dar buen dejo a esta Mansión" (I: 297) dice Arsenio, y parece que es él quien tiene las Mansiones en su poder. ${ }^{18}$ Pero en el mismo párrafo, el narrador reasume su papel diciendo "el soneto [...] es el siguiente con que tendrá fin esta Mansión”. En otra ocasión, Don Pedro asume no solamente el papel de quien organiza y ordena los recitales de versos, sino también el del narrador omnisciente que sabe cómo se sienten sus personajes: "pues yo ofresco [...] dezir vna canción famosa de S. Joan de Clímaco, con que se dará feliz fin al camino, y llegaremos al puerto desseado, sin aver sentido fatiga alguna" (I: 481). La voz del narrador invade a los personajes y los personajes se convierten en narradores, pasando así del nivel de representación al nivel de escritura. Es el dialogismo bakhtiniano al revés: no se relativiza la voz del narrador, sino que los personajes adquieren algo de la autoridad del narrador. Al multiplicarse el universo (social y lingüístico) del narrador para incluir a todos los personajes, el diálogo se convierte en monólogo. La voz humana no se da sino en una pluralidad perecedera, el vocerío humano que distrae de la voz de Dios. ${ }^{19}$ Será por eso que el monólogo es superior al diálogo, y la cúspide de la perfección es el silencio - tesis que se promueve en innumerables elogios del silencio y de la soledad a lo largo del texto. ${ }^{20}$

\footnotetext{
${ }^{18}$ Compárense I: 297, y I: 481 donde Don Pedro se convierte en narrador.

${ }^{19}$ Compárese también el uso de "voz" y "escribir" en la exhortación poética (II: 790), donde parece que es Dios quien habla, y el hombre quien escribe.

${ }^{20}$ Las siguientes referencias no son sino una selección fortuita: II: $178-9 ; 181 ; 308 ; 327-330 ; 800$; 826. Obviamente, muchas referencias mencionadas ya al discutir la concepción del signo, el significado de la poesía, etc. vendrían al caso aquí también. Llama la atención, sin embargo, que los elogios del silencio son mucho más frecuentes hacia el final de la obra.
} 
Como en el caso de la multiplicidad de los signos, hay una multitud de voces destinadas para ser reducidas a una sola voz. Este proceso de reducción, sin embargo, tiene que partir de la multitud. Empieza la voz del narrador, sigue la de Andrés, después las de los compañeros de Andrés, después la voz del ermitaño, las de los personajes de los cuentos intercalados, las de los autores originales de las poesías intercaladas, las de los Padres de la Iglesia Católica, los monjes del convento, y todas las otras voces textuales e intertextuales. Este proceso es el resultado del hecho de que la concepción literaria-artística heredada es inadecuada para los propósitos y las creencias del autor, lo que le obliga a asimilar las formas a su mundo espiritual de la Contrarreforma. La estructura generadora del texto es el diálogo, pero la estructura generada es, a fin de cuentas, monológica.

\section{REALIDAD Y FICCIÓN}

Todas las preocupaciones meta-narrativas, el problema del diálogo, del signo, de los géneros literarios, convergen en un punto: la ficcionalidad del texto. Las contradicciones culminan en una ambigüedad decididamente irresuelta frente a la realidad, lo que convierte al texto finalmente en un proyecto interminable.

A lo largo del texto encontramos varias indicaciones de que la ficción posiblemente no sea ficción del todo, o que parte del texto sea verdad histórica, aunque nunca se sabe con exactitud si tal vez se trate de un juego meta-ficticio. La ficción de primer grado está constantemente amenazada, por un lado, por la intrusión de los meta-niveles de la reflexión, por otro lado, por la intrusión de la realidad. Después de un recital de poesía, el narrador dice que Antonio lo copia "como avía hecho [con] todos los demás versos que se avían hecho aquellos días, porque Don Pedro se lo avía encargado; que ya iba texiendo en su mente esta relación que de successos tan entretenidos y dignos de memoria se va haziendo" (I: 322).

Los indicios aparecen más frecuentemente hacia el final de la obra, junto con una mayor frecuencia de intervenciones del narrador como organizador del texto. Es en el último cuarto de $E l$ desierto prodigioso que encontramos la nota tal vez más explícita: "(que ya no es justo que dissimule los nonbres propios como enpezé al principio)" (II: 446). Evidentemente, esto se puede leer como la revelación de que la narración es en realidad (auto)biografía y lo que parecía ficción es historiografia (aunque el hecho de que está puesto entre paréntesis ya nos previene de que este giro no sea tan inequívoco). Si lo fuera, aquel personaje que ya conocemos como Don Pedro sería el mismo autor, y tal vez el narrador. En favor de esta interpretación se puede señalar el comentario auto-irónico (el contexto es un viaje de los personajes) que sigue inmediatamente al pasaje entre paréntesis citado arriba: "Ya se deja entender aquí que su hermano Don Pedro no necessitaba de combite para empeño tan de su obligación y de su gusto". La "obligación" será la del historiógrafo que no necesita invitación; y del "gusto" ya sabemos de aquel "furor poético" que le hace apuntarlo todo. Ahora, investigaciones históricas han podido probar la existencia de muchos personajes del marco narrativo. También se sabe que varios episodios (por ejemplo el traslado del arzobispo muerto a España) ocurrieron en la época en cuestión (Páramo Pomareda LX et seq.). No cabe duda, entonces, que El desierto prodigioso tiene muchos puntos de conexión con la vida del autor. Pero quedan como figuras problemáticas 
Pedro y Arsenio: Arsenio, porque parece ser el único personaje inventado ${ }^{21}$ y Pedro, porque vacila entre el personaje ficticio Don Pedro, y la persona real Pedro de Solís y Valenzuela, creador de Don Pedro. Lo que llama la atención en el caso de Pedro es el hecho de que nunca se afirma la identidad de las tres instancias personaje/narrador/autor por completo. Encontramos más que nada alusiones al proceso de escritura y al origen del material. Baste aquí un ejemplo para ilustrar esta técnica alusiva: "Y porque a la curiosidad de Don Pedro no se le escapó lo que representó esta danza, [...] quiero que tanbién no se le escape a mi letor, y assí la pongo aquí" (II: 523 et seq.). Parece que Don Pedro y el narrador son personajes ciertamente paralelos, pero no idénticos. Cabe recordar también que Don Pedro es autor ficticio de versos cuya autoría Pedro de Solís nunca hubiera reclamado.

¿Por qué, entonces, estas ambigüedades? Bien se sabe que la ficción no estaba en la más alta estimación en aquella época ni en España ni, aún menos, en el Nuevo Mundo. ¿Por qué no despejó Pedro de Solís su texto de los vestigios de la ficción novelesca, y escribió una crónica, un texto autobiográfico, o historiográfico? No podemos sino especular sobre posibles razones personales y psicológicas. ${ }^{22}$ Más allá de lo accidental podemos señalar, sin embargo, ciertas características formales de la obra que posiblemente explican el estatus ambiguo del texto. En la ficción narrativa la unificación de lenguajes se presenta como proceso en vez de resultado (al contrario de la historiografia). La narrativización abre la posibilidad de jerarquizar los discursos claramente, desde el diálogo estilizado y el monólogo secular hasta el monólogo oración y el silencio meditativo, y de esta manera está al servicio de la tendencia moralizante. Otra razón en favor de la narrativización ficticia o semi-ficticia tiene que ver con la posición del narrador. Al disociarse de los personajes, el autor puede eliminar el punto de vista personal subjetivo, es decir eliminar la voz individual que es constitutiva, por ejemplo, en una narración autobiográfica. Así la ficción sirve para realizar el proyecto de la unificación de los lenguajes y su subordinación a la verdad objetiva de la fe. Incluso más importante es, en mi opinión, la disolución misma de la dicotomía entre realidad y ficción, lo que permite la introducción del estilo como término intermedio. El estilo es el espacio donde literatura de ficción e Iglesia de la Contrarreforma pueden convivir. Ficción y veracidad, fantasía y solemnidad, creación y sumisión no se contradicen en el reino estilístico de la literatura culta religiosa.

Otras razones para la vuelta a la realidad se vinculan con el ascetismo de la obra. Es muy instructiva la siguiente carta de Fernando, escrita cuando ya está en un monasterio en España, casi al final de la obra:

le pidas [al padre] que illustre el soliloquio que yo he formado en prosa con algunos versos dulzes, $[\ldots]$ porque yo, attendiendo a otros ejercicios de más profundidad, ya no hago versos ni trato de esso (II: 811 ).

\footnotetext{
${ }^{21}$ Briceño Jáuregui sugiere que hay un modelo para Arsenio en un monje histórico, llamado Domingo de Betanzos, en el convento de La Candelaria en Nueva Granada (355). Pero la relación entre el modelo real y el protagonista es mucho más vaga aquí que en el caso de los otros personajes que no han sufrido un cambio de nombre.

${ }^{22}$ Páramo Pomareda trata de explicar El desierto prodigioso reconstruyendo la relación entre Pedro de Solís y su hermano mayor, Fernando, y apelando algunos eventos históricos que debieron haber impresionado al autor en su juventud (LVIII-LXXIII).
} 
Don Pedro se pone a escribir para convencer a su hermano de que le mande más material. El narrador comenta más tarde:

Estos versos hizo Don Pedro con desseo de animar a su hermano para que cuydasse de su retribución en otros de su ingenio, [...] mas no lo consiguió, porque el nuevo estado le induxo a la seriedad que professa su silencio [...] (II: 826).

El personaje ejemplar, Fernando, se ha retirado del hablar y escribir versos, y lo único que quiere producir es un "soliloquio", lo cual confirma una vez más la sospecha arraigada frente a la palabra poética y el diálogo. Y no parece ser casualidad el hecho de que esto ocurra casi al final del marco narrativo, cuando más y más elementos de la trama parecen haberse despojado de la máscara de la ficción. La desnarrativización empezó con las alusiones a la base histórica de los hechos y a las fuentes de información y culminó en la revelación de la identidad verdadera de los personajes. Los personajes empiezan a vivir según la moral establecida como ideal. Hay más y más intervenciones del narrador, y ya no es una sorpresa que su tema preferido sea la composición de "algunas mansiones, como las del Desierto Prodigioso" (II: 811) o la organización del material para el segundo tomo. Con otras palabras: la trama moral se ha agotado con la muerte de Arsenio y la conversión a la vida monástica de toda la familia Solís. ${ }^{23}$ Llegado a este punto, el texto ya no integra sermones, sino se convierte en sermón y últimamente en monólogo oración, con ligaduras reflexivas que tratan precisamente de cómo ligar y organizar las partes heterogéneas. Ya no puede haber desarrollo. Otra vez vemos la contradicción fundamental de la obra, pues termina la narración, pero no puede terminar la interpretación de los signos, ni la adaptación y traducción de géneros al ámbito de la literatura religiosa. La narración cede el paso a la moralización, pero la obra misma —el proyecto- se muestra interminable. Así, la trayectoria de los personajes como seres ficticios al servicio de la moral cristiana ha llegado a su fin. Lo que queda, a pesar del cerramiento ideológico a nivel de la trama, es el "furor poético" del autor - y el plan de escribir el segundo tomo, en el que, podemos especular, hubiera seguido traduciendo géneros, glosando versos, $\mathrm{y}$ creando espacios para la literatura.

Mi agradecimiento a Flor María Rodríguez-Arenas por su minuciosa lectura de varias versiones de este artículo, y su amable apoyo.

\section{Obras Consultadas}

Bakhtin, Mikhail. The Dialogic Imagination. Austin: University of Texas Press, 1981. Briceño Jáuregui, Manuel, S.I. Estudio histórico-crítico de El desierto prodigioso y prodigio del desierto. Bogotá: Caro y Cuervo, 1983.

Carilla, Emilio. La literatura barroca en Hispanoamérica. New York: Anaya, 1972.

Chibán, Alicia, Elena Altuna. "La transtextualidad del Siglo de Oro español en El desierto prodigioso". Thesaurus. Boletín del Instituto Caro y Cuervo 44 (1989): 567-579.

\footnotetext{
${ }^{23}$ La única excepción es la madre. A no ser que se quiera contar el dar licencia a su marido de abandonarla e irse al Desierto Prodigioso como ermitaño, ella no alcanza el estatus de personaje activo.
} 
Foucault, Michel. The Order of Things: An Archeology of the Human Sciences. New York: Vintage, 1973.

Gardiner, Eileen, editora. Visions of Heaven and Hell before Dante. New York: Italica Press, 1989.

Goic, Cedomil. "La novela hispanoamericana colonial". Historia de la literatura hispanoamericana. Tomo I: Época colonial. Madrid: Cátedra, 1982. 369-406.

Joset, Jacques. Introducción. El viaje entretenido de Agustín Rojas Villandrando. Madrid: Espasa-Calpe, 1977. VII-LXIII.

Le Goff, Jacques. The Birth of Purgatory. Chicago: University of Chicago Press, 1984.

Maravall, José Antonio. La cultura del Barroco. Análisis de una estructura histórica. Barcelona: Ariel, 1975.

Martínez-Bonati, Félix. "Cervantes y las regiones de la imaginación”. Dispositio 2 (1977): 28-53.

Orjuela, Héctor H. Introducción. El desierto prodigioso y prodigio del desierto de Pedro Solís y Valenzuela. Primera novela hispanoamericana. Bogotá: Caro y Cuervo, 1984.

Páramo Pomareda, Jorge. Introducción. El desierto prodigioso y el prodigio del desierto. Rubén Páez Patiño (editor), introducción y notas Jorge Páramo Pomareda, Manuel Briceño Jáuregui, Rubén Páez Patiño. 3 volúmenes hasta ahora. Bogotá: Caro y Cuervo, 1977.

Rodríguez-Arenas, Flor María. "El desierto prodigioso y el prodigio del desierto o Contrarreforma y Barroco en la Nueva Granada". De próxima publicación en las Actas del XXVIII Congreso del Instituto Internacional de Literatura Iberoamericana, 18-21 de junio, 1990.

Rojas Villandrando, Agustín. El viaje entretenido. 1602-3. Edición, introducción y notas Jacques Joset. Madrid: Espasa-Calpe, 1977.

Solís y Valenzuela, Pedro de. El desierto prodigioso y prodigio del desierto. Rubén Páez Patiño (editor), introducción y notas Jorge Páramo Pomareda, Manuel Briceño Jáuregui, Rubén Páez Patiño. 3 volúmenes hasta ahora. Bogotá: Caro y Cuervo, 1977. 
